\title{
Correlation between the patients with Hepatitis C Virus and their Health-Related Quality of Life
}

\author{
Ola Omer Abd ElHamied ${ }^{1}$; Hala Ibrahem Mohamed ${ }^{2}$; Hend Elham Mohamed ${ }^{3}$; Eman Fadl Abd Elkhalik ${ }^{4}$
}

(1) Bachalor of nursing Minia University - Egypt

(2) Professor of Tropical Medicine Department- Faculty of Medicine- Minia University, Egypt

(3) Assist. Professor of Medical Surgical Nursing - Faculty of Nursing - Minia University, Egypt

(4) Lecturer of Medical Surgical Nursing - Faculty of Nursing - Minia University, Egypt

\begin{abstract}
Background: Hepatitis $\mathrm{C}$ virus (HCV) infection is a global health problem and a major cause of morbidity and mortality. The current study aimed to assess the correlation between the patients with the hepatitis $\mathrm{C}$ virus and their health-related quality of life. Descriptive design was used. Setting: Carried out at liver virology outpatient. Subject: A convenient sample of two hundred adult patients with HCV newly received Sofosbuvir and Daclatasvir. Tools: Interview questioner and medical data sheet and Short-Form health survey (SF-36) questionnaire. Results: An improvement in the total quality of life this appear through $51.0 \%$ of hepatitis patients were poor in quality of life before treatment with Sofosbuvir and Daclatasvir medication while $(62.0 \%)$ of them become excellent in quality of life after 3 months from treatment with highly statistically significant differences. Also, there was a fair negative association between the duration of disease of the studied patients with their total quality of life measured by shortform of health before administration of treatment with Sofosbuvir and Daclatasvir. Conclusion: The study concluded that the administration of Sofosbuvir and Daclatasvir for patients had positive effect on their quality of life especially for newly diagnosed patients. Recommendation: The study recommended that early screening for hepatitis $\mathrm{C}$ to begin early suitable treatment.
\end{abstract}

Keywords: Correlation, Hepatitis C Virus, Quality of Life

\section{Introduction}

Hepatitis $\mathrm{C}$ virus (HCV) infection is a global health problem and a major cause of morbidity and mortality (Faddan, et al., 2019), Egypt has the highest prevalence of Hepatitis C in the world. Overall, estimates of the HCV rate in the general population have ranged between 10 and 20 percent. Geographically, the Hepatitis C prevalence is higher in Lower Egypt (Nile Delta) than in Upper Egypt and lower in urban compared to rural areas. The economic burden is multiplied by the impact of $\mathrm{HCV}$ on health-related quality of life (HRQoL), appreciable at any stage of severity (Omran et al., 2018).

In Egypt, a cross-sectional survey of 21 governorates was done by El-Ghitany and Farghaly, (2019) to determine geospatial epidemiology of hepatitis $\mathrm{C}$ infection in Egypt found that the participant's age ranged from 14-90 years, the darkest spot of HCV infection in Menoufeya $(37.8 \%)$ followed by Beni Suef (29.2\%) and Minia (28.6\%), and anti$\mathrm{HCV}$ prevalence was higher among males.

Quality of Life (QOL) is a popular term that conveys an overall sense of well-being, including aspects of happiness and satisfaction with life as a whole. It is broad and subjective rather than specific and objective. The Complications of advanced liver disease such as encephalopathy, variceal hemorrhage, and ascites have been reported to negatively affect HRQoL. Extra-hepatic manifestations related to HCV as fatigue, irritability, depression, muscle pain, joint pain, and cognitive impairment may also influence the patient's psychological well-being and self-perceived health (Jain, et al., 2019).

Chronic infection with HCV has a profound effect on health-related quality of life (HRQoL) - with fatigue, depression, and neurocognitive deficits among the most common complaints. Neuropsychiatric symptoms have prompted research to determine whether the HCV acts within the central nervous system. The replicating virus has been found in central nervous tissues, and changes in neurotransmitter levels in the frontal white matter of patients with chronic hepatitis $\mathrm{C}$ are correlated with impaired attention and concentration (Youssef, et al., 2017).

Although treatment-related adverse effects may dissuade people from starting therapy and reduce compliance with associated reductions in sustained viral response, for the majority of patients' viral clearance produces improvements in both HRQoL and long-term prognosis. Novel agents, with improved adverse effect profiles, may allow more patients to achieve a sustained viral response (Zainulabid, 2019).

The nurse must participate in educating individuals with $\mathrm{HCV}$ infection to improve HRQL through lifestyle changes initiated through behavioral modification. For example, education on the monitoring of symptoms such as fatigue, body pain, depression, and lack of ability to function effectively. Previous research has shown that individuals chronically infected with $\mathrm{HCV}$ respond to interventions focused on increasing knowledge and this, improves functional status and HRQL of individuals with chronic HCV (Youssef et al., 2017).

\section{Significance of the Study:}

According to a recent survey done in Egypt, 2015 found the prevalence rate among the population aged from 159 years (sample size 1,466) in Minia governorate was $9.0 \%$ of them have positive $\mathrm{HCV}$ antibody and $6.1 \%$ have positive HCV RNA test. HCV has a major impact on the quality of life and can cause patients significant distress. So, this study will be carried out to investigate the effect of $\mathrm{HCV}$ infection on HRQOL among patients. Multiple studies worldwide have shown that chronic hepatitis $\mathrm{C}$ is associated with considerable impairment of HRQoL (Ministry of Health and Population et al., 2015). 


\section{Aim of the study:}

Assess the correlation between the patients with Hepatitis C Virus and their Health-Related Quality of Life.

\section{Research question:}

Is there a correlation between the patients with Hepatitis C Virus and their Health-Related Quality of Life impairment?

\section{Research Design:}

A Descriptive research design was utilized

\section{Subjects}

A convenient sample of two hundred adult patients with HCV newly received Sofosbuvir and Daclatasvir.

\section{Inclusion criteria :}

- Adult patient from18- 60 years

- Conscious and oriented

- The patient has early stage of chronic hepatitis C

- Newly received Sofosbuvir and Daclatasvir medication.

\section{Exclusion criteria:}

- Musculoskeletal problems.

- Pregnant women.

- Other hepatitis viruses

- Immunocompromised diseases.

- Obesity (overweight $25 \mathrm{~kg}$ ) and underweight patients.

- Patients with speech and mental disorders.

\section{Setting :}

The study was conducted in liver virology outpatients' clinic at Minia University Hospital and Fever Hospital related to ministry of health.

\section{Study duration:}

The total data collections were collected over period of 12 months starting from December 2018 to December 2019.

\section{Data Collection Tools :}

The current study data were collected by Two tools were designed, prepared, tested, and used for collecting data in this study after extensive reading in the literature review by the investigator (Rand Corporation, 2013).

Tool I: Bio-socio-demographic characteristics were included in two parts (Appendix B)

$\mathbf{1}^{\text {st }}$ part: sociodemographic data : sex, age, marital status, education level, occupation, and residence

$2^{\text {nd }}$ part: Medical information include: past and present medical history, including medical diagnosis, smoking, medication

Tool II: A Short-Form health survey (SF-36) questionnaire arabic version adopted by Ware and Sherbourne, (1992) \& McHorney et al. (1994) to measure the quality of life for patients with hepatitis $\mathrm{C}$ virus which include eight health domains: physical functioning (ten items from $\mathrm{Q} 3$ to $\mathrm{Q} 12$ ), physical role problems (four items from Q 13 to Q 16) and due to emotional problems (three items from Q 17 to Q 19), energy or fatigue (four items: Q 23, 27, 29, 31), emotional wellbeing (five items Q 24- 26, Q 28, Q 30), social functioning (two items, Q 20, Q 32), Bodily Pain (two items, Q 21 \& Q 22), and general health perceptions (five items: Q 1 and from Q33 to Q 36), which Q 2 refer to current patient health compared to one year ago.

\section{Scoring system}

Each subscale is scored from (0 to 100) when patient assessment indicates score 0 this means the worst score for quality of life but when have 100 mean they have the best score for quality of life. While the total scores were less than $50 \%$ considered as poor quality of life. If the total scores ranged from $50 \%-75 \%$ considered as good quality of life, and when the total scores were $75 \%$ or more considered as excellent quality of life.

\section{Tool Validity and Reliability:}

A panel of five experts in the field of medical surgicalnursing staff to examine validity of the content. No alterations of the content were be done allowing to the panel judgment on the clearness of sentences, suitability of the content, and categorization of items. Reliability was done by using the alpha Cronbach's test was .81 and it examined by many studies was 0.80 by McHorney et al. (1994)

\section{Pilot Study :}

Was conducted for $10 \%$ (20 patients) of the total sample to test the study process and to evaluate the efficiency of tools.

\section{Procedure:}

The researcher met the patients during a time of outpatient clinics, introducing herself, and explained the purpose and nature of the study. oral consent was obtained to participate in this study. The researcher started a collection of data in 12 months by using Bio-socio-demographic characteristics for 15- 20 minutes for each patient. The researcher distributed the data collection sheets to respondents individually in the reception in the liver virology outpatient patient clinics at Minia university hospital and fever hospital. Collection of the study data was done on daily basis (2 to 3 days /week) during the morning shift. The researcher checked the completeness of each filled form after the participant filled it. Health-related quality of life was measured for every patient before and after 3 months from finishing the treatment.

\section{Statistical data}

Statistical analysis was done by using Statistical Package for the Social Science (SPSS IBM 25.0). Quality control was done at the stages of coding and data entry. Data were presented by using descriptive statistics in the form of frequencies and percentages for qualitative variables and mean \& standard deviation (SD) for quantitative variables. Chisquare $\left(\mathrm{x}^{2}\right)$ was used to test the association between two qualitative variables. T-test was used to measure mean differences of quality of life measured by short-form questionnaire (SF-36) between before and after treatment Graphs were done for data visualization using Microsoft Excel. The P-value of $\leq 0.05$ indicates a significant result while the $\mathrm{P}$-value of $>0.05$ indicates a non-significant result. 
Minia Scientific Nursing Journal (Print - ISSN 2537-012X) (Online - ISSN 2785-9797) Vol. (8) No. (1) December 2020

\section{Results:}

Table (1): Percentage distribution of Bio-socio-demographic characteristics of the studied Sample $(\mathbf{n}=\mathbf{2 0 0})$

\begin{tabular}{|c|c|c|}
\hline Items & NO. & $\%$ \\
\hline \multicolumn{3}{|l|}{ Age } \\
\hline $20-30$ & 34 & 17.0 \\
\hline $31-40$ & 58 & 29.0 \\
\hline $41-50$ & 52 & 26.0 \\
\hline $51-60$ & 56 & 28.0 \\
\hline Mean \pm SD & \multicolumn{2}{|c|}{$33.4 \pm 8.1$ years } \\
\hline \multicolumn{3}{|l|}{ Sex } \\
\hline Man & 124 & 62.0 \\
\hline Woman & 76 & 38.0 \\
\hline \multicolumn{3}{|l|}{ Marital Status } \\
\hline Single & 24 & 12.0 \\
\hline Married & 160 & 80.0 \\
\hline Widow & 16 & 8.0 \\
\hline \multicolumn{3}{|l|}{ Educational level } \\
\hline Illiterate & 28 & 14.0 \\
\hline Basic & 38 & 19.0 \\
\hline Diplom & 82 & 41.0 \\
\hline Bachelor & 52 & 26.0 \\
\hline \multicolumn{3}{|l|}{ Residence } \\
\hline Urban & 32 & 16.0 \\
\hline Rural & 168 & 84.0 \\
\hline \multicolumn{3}{|l|}{ Occupation } \\
\hline Jobless & 136 & 68.0 \\
\hline Work & 64 & 32.0 \\
\hline
\end{tabular}

Table (1): presents that $29.0 \%$ of the studied patient their age ranged between $31-40$ years with mean $33.4 \pm 8.1$ years, $62.0 \%$ of them was man. The highest percentage of the study sample were married and lived in rural areas constituted $(80.0 \% \&$ $84.0 \%$ respectively). Related to occupation status found that two-third (68.0\%) of the study sample were jobless.

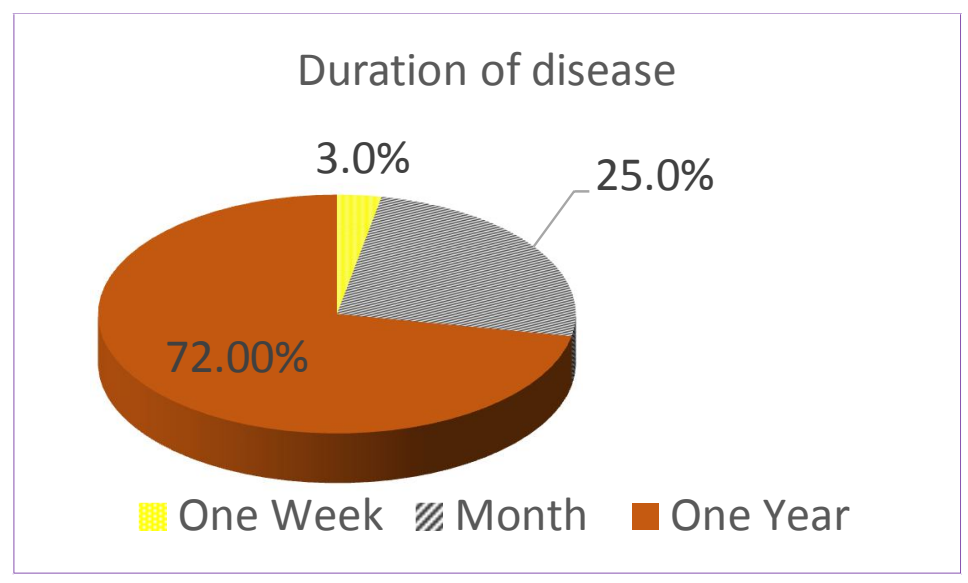

Figure (1): Percentage distribution of studied Sample regarding the duration of disease $(\mathbf{n}=\mathbf{2 0 0})$

Figure (1): illustrates that near to three quarters $(72.0 \%)$ of the studied sample have duration of their disease from one year ago, while $25.0 \%$ of them from one month, and a minority of them from one week.

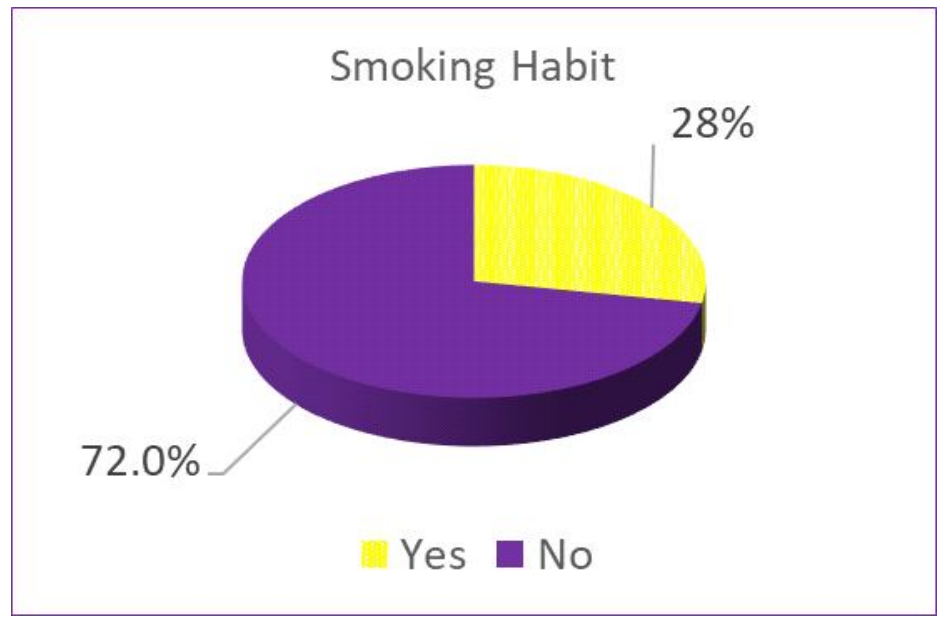

Figure (2): Percentage distribution of studied Sample regarding smoking habit $(\mathrm{n}=\mathbf{2 0 0})$ 
Minia Scientific Nursing Journal (Print - ISSN 2537-012X) (Online - ISSN 2785-9797) Vol. (8) No. (1) December 2020

Figure (2): demonstrates that near to three quarters (72.0\%) of the studied patient was not smokers and more than one-quarter $(28.0 \%)$ of them was smoker.

Table (2): Mean scores of quality of life domain of the studied sample before and after 3 months from the administration of treatment

\begin{tabular}{|c|c|c|c|c|}
\hline Quality of life domains & Before treatment & $\begin{array}{c}\text { Three months after } \\
\text { treatment }\end{array}$ & t-test & $P$-value \\
\hline Physical functioning & $47.1 \pm 28.9$ & $89.4 \pm 12.7$ & 13.401 & $.0001 * *$ \\
\hline Role limitations due to physical health & $42.8 \pm 44.4$ & $70.8 \pm 41.4$ & 4.609 & $.0001 * *$ \\
\hline Role limitations due to emotional problems & $57.0 \pm 59.2$ & $94.3 \pm 55.3$ & 4.609 & $.0001 * *$ \\
\hline Energy & $59.0 \pm 30.7$ & $77.6 \pm 22.4$ & 4.899 & $.0001 * *$ \\
\hline Fatigue & $44.7 \pm 33.0$ & $25.4 \pm 28.2$ & 4.446 & $.0001 * *$ \\
\hline Emotional wellbeing & $44.4 \pm 25.4$ & $64.7 \pm 22.5$ & 5.997 & $.0001 * *$ \\
\hline Social functioning & $53.5 \pm 29.9$ & $75.8 \pm 25.7$ & 5.647 & $.0001 * *$ \\
\hline Pain & $59.8 \pm 35.5$ & $81.2 \pm 26.1$ & 4.841 & $.0001 * *$ \\
\hline General health & $45.7 \pm 19.2$ & $58.4 \pm 18.4$ & 4.769 & $.0001 * *$ \\
\hline Total SF-36 & $47.6 \pm 24.9$ & $75.6 \pm 19.2$ & 8.888 & $.0001 * *$ \\
\hline
\end{tabular}

Table (2): reveals that the total mean score of quality of life domain after 3 months of treatment with Sofosbuvir and Daclatasvir medication was higher than before treatment constitute $(75.6 \pm 19.2 \& 47.6 \pm 24.9)$ respectively with highly statistically significant (0.001).

Table (3 Relation between total Quality of life of the studied sample and their bio-socio-demographic characteristics before administration of Sofosbuvir and Daclatasvir $(n=200)$.

\begin{tabular}{|c|c|c|c|c|c|c|c|c|c|}
\hline \multirow{3}{*}{$\begin{array}{c}\text { Bio-socio-demographic } \\
\text { characteristics }\end{array}$} & & \multicolumn{6}{|c|}{ Quality of life Before treatment } & \multirow{3}{*}{$X^{2}$} & \multirow{3}{*}{$P$-value } \\
\hline & & \multicolumn{2}{|c|}{ Poor $(n=102)$} & \multicolumn{2}{|c|}{$\begin{array}{c}\text { Good } \\
(n=66) \\
\end{array}$} & \multicolumn{2}{|c|}{$\begin{array}{c}\text { Excellent } \\
(\mathrm{n}=32) \\
\end{array}$} & & \\
\hline & NO. & No. & $\%$ & No. & $\%$ & No. & $\%$ & & \\
\hline \multicolumn{10}{|l|}{ Age/ Years } \\
\hline $20-30$ & 34 & 12 & 35.3 & 10 & 29.4 & 12 & 35.3 & \multirow{4}{*}{18.438} & \multirow{4}{*}{$.005 * *$} \\
\hline $31-40$ & 58 & 40 & 69.0 & 8 & 13.8 & 10 & 17.2 & & \\
\hline $41-50$ & 52 & 28 & 53.8 & 16 & 30.8 & 8 & 15.4 & & \\
\hline $51-60$ & 56 & 22 & 39.3 & 32 & 57.1 & 2 & 3.6 & & \\
\hline \multicolumn{10}{|l|}{ Gender } \\
\hline Male & 124 & 54 & 43.5 & 50 & 40.3 & 20 & 16.2 & \multirow[t]{2}{*}{4.429} & .109 \\
\hline Female & 76 & 48 & 63.2 & 16 & 21.0 & 12 & 15.8 & & NS \\
\hline \multicolumn{10}{|l|}{ Marital Status } \\
\hline Single & 24 & 10 & 41.7 & 6 & 25.0 & 8 & 33.3 & \multirow{3}{*}{5.192} & \multirow{3}{*}{$\begin{array}{l}.268 \\
\text { NS } \\
\end{array}$} \\
\hline Married & 160 & 80 & 50.0 & 56 & 35.0 & 24 & 15.0 & & \\
\hline Widow & 16 & 12 & 75.0 & 4 & 25.0 & 0 & .0 & & \\
\hline \multicolumn{10}{|l|}{ Educational level } \\
\hline Illiterate & 28 & 6 & 21.4 & 20 & 71.4 & 2 & 7.2 & \multirow{4}{*}{18.662} & \multirow{4}{*}{$.005^{* *}$} \\
\hline Basic & 38 & 24 & 63.1 & 6 & 15.8 & 8 & 21.1 & & \\
\hline Diplom & 82 & 34 & 41.5 & 32 & 39.0 & 16 & 19.5 & & \\
\hline Bachelor & 52 & 38 & 73.1 & 8 & 15.4 & 6 & 11.5 & & \\
\hline \multicolumn{10}{|l|}{ Residence } \\
\hline Urban & 32 & 18 & 56.3 & 4 & 25.0 & 3 & 18.7 & \multirow[t]{2}{*}{.562} & \multirow[t]{2}{*}{.755} \\
\hline Rural & 168 & 84 & 50.0 & 29 & 34.5 & 13 & 15.5 & & \\
\hline \multicolumn{10}{|l|}{ Occupation } \\
\hline Jobless & 136 & 70 & 51.5 & 20 & 29.4 & 13 & 19.1 & \multirow{7}{*}{17.957} & \multirow{7}{*}{$\begin{array}{l}.06 \\
\text { NS }\end{array}$} \\
\hline Worker & 6 & 6 & 100. & 0 & .0 & 0 & .0 & & \\
\hline Nursing & 12 & 4 & 33.3 & 6 & 50.0 & 2 & 16.7 & & \\
\hline Security & 6 & 0 & .0 & 6 & 100 & 0 & .0 & & \\
\hline Teacher & 22 & 16 & 72.7 & 4 & 18.2 & 2 & 9.1 & & \\
\hline Office worker & 14 & 4 & 28.6 & 10 & 71.4 & 0 & .0 & & \\
\hline Driver & 4 & 2 & 50.0 & 0 & .0 & 2 & 50.0 & & \\
\hline
\end{tabular}

Chi-test for qualitative variables NS = not statistically significant differences ** Highly statistically significant differences

Table (3): shows that, $69.0 \%$ of studied patient who aged between $31-40$ years and $53.8 \%$ of the studied patient who aged between 41- 50 years had a poor total quality of life before administration of treatment with Sofosbuvir and Daclatasvir medication, and $73.1 \%$ of them who had bachelor degree and $63.1 \%$ of them who had basic education had poor quality of life before treatment with statistically significant differences ( 0.005 and 0.005$)$ respectively.

Table (4): Relation between total Quality of life of the studied sample and their bio-socio-demographic characteristics 3 months after the administration of Sofosbuvir and Daclatasvir $(n=200)$.

\begin{tabular}{|c|c|c|c|c|c|c|c|c|c|}
\hline \multirow{3}{*}{ Items } & & \multicolumn{6}{|c|}{ Quality of life 3 months after-treatment } & \multirow[t]{3}{*}{$\mathbf{X}^{2}$} & \multirow[t]{3}{*}{$P$-value } \\
\hline & & \multicolumn{2}{|c|}{ Poor $(n=26)$} & \multicolumn{2}{|c|}{$\begin{array}{c}\text { Good } \\
(n=50)\end{array}$} & \multicolumn{2}{|c|}{$\begin{array}{l}\text { Excellent } \\
(n=124)\end{array}$} & & \\
\hline & NO. & No. & $\%$ & No. & $\%$ & No. & $\%$ & & \\
\hline \multicolumn{10}{|l|}{ Age/ Years } \\
\hline $20-30$ & 17 & 2 & 1.0 & 6 & 3.0 & 26 & 13.0 & \multirow[t]{2}{*}{7.522} & .275 \\
\hline $31-40$ & 19 & 8 & 4.0 & 14 & 7.0 & 36 & 18.0 & & NS \\
\hline
\end{tabular}


Minia Scientific Nursing Journal (Print - ISSN 2537-012X) (Online - ISSN 2785-9797) Vol. (8) No. (1) December 2020

\begin{tabular}{|c|c|c|c|c|c|c|c|c|c|}
\hline \multirow{3}{*}{ Items } & & \multicolumn{6}{|c|}{ Quality of life 3 months after-treatment } & \multirow[t]{3}{*}{$\mathrm{X}^{2}$} & \multirow[t]{3}{*}{$P$-value } \\
\hline & & \multicolumn{2}{|c|}{ Poor $(n=26)$} & \multicolumn{2}{|c|}{$\begin{array}{c}\text { Good } \\
(n=50)\end{array}$} & \multicolumn{2}{|c|}{$\begin{array}{l}\text { Excellent } \\
(\mathrm{n}=124) \\
\end{array}$} & & \\
\hline & NO. & No. & $\%$ & No. & $\%$ & No. & $\%$ & & \\
\hline $41-50$ & 26 & 4 & 2.0 & 10 & 5.0 & 38 & 19.0 & & \\
\hline $51-60$ & 28 & 12 & 6.0 & 20 & 10.0 & 24 & 12.0 & & \\
\hline \multicolumn{10}{|l|}{ Gender } \\
\hline Male & 124 & 12 & 6.0 & 26 & 13.0 & 86 & 43.0 & \multirow[t]{2}{*}{3.870} & .144 \\
\hline Female & 66 & 14 & 7.0 & 24 & 12.0 & 38 & 19.0 & & NS \\
\hline \multicolumn{10}{|l|}{ Marital Status } \\
\hline Single & 24 & 2 & 1.0 & 8 & 4.0 & 14 & 7.0 & \multirow[t]{3}{*}{1.737} & \multirow{3}{*}{$\begin{array}{l}.784 \\
\text { NS }\end{array}$} \\
\hline Married & 160 & 20 & 10.0 & 38 & 19.0 & 102 & 51.0 & & \\
\hline Widow & 16 & 4 & 2.0 & 4 & 2.0 & 8 & 4.0 & & \\
\hline \multicolumn{10}{|l|}{ Educational level } \\
\hline Illiterate & 28 & 4 & 2.0 & 14 & 7.0 & 10 & 5.0 & \multirow{4}{*}{11.277} & \multirow{4}{*}{$\begin{array}{l}.080 \\
\text { NS }\end{array}$} \\
\hline Basic & 38 & 4 & 2.0 & 12 & 6.0 & 22 & 11.0 & & \\
\hline Diplom & 82 & 6 & 3.0 & 14 & 7.0 & 62 & 31.0 & & \\
\hline Bachelor & 52 & 12 & 6.0 & 10 & 5.0 & 30 & 15.0 & & \\
\hline \multicolumn{10}{|l|}{ Residence } \\
\hline Urban & 32 & 8 & 4.0 & 10 & 5.0 & 14 & 7.0 & \multirow[t]{2}{*}{3.431} & .180 \\
\hline Rural & 168 & 18 & 9.0 & 40 & 20.0 & 110 & 55.0 & & NS \\
\hline
\end{tabular}

Chi-test for qualitative variables NS = not statistically significant differences

Table (4): reveals that there were no statistically significant total Quality of life of the studied sample and their sociodemographic characteristics 3 months after the administration of treatment.

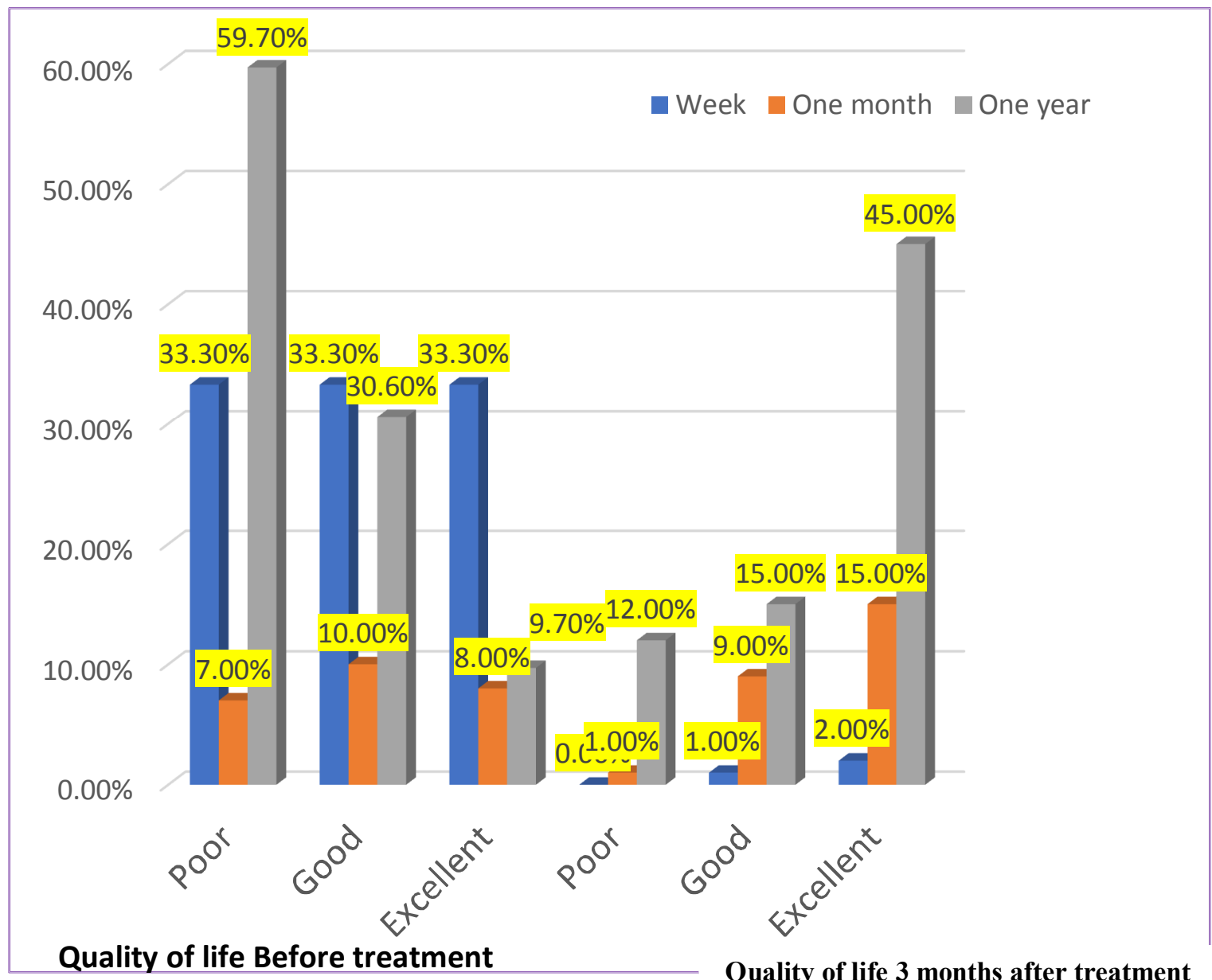

Figure (3): Comparison between total Quality of life of the studied sample and their duration of disease before and after 3 months administration of Sofosbuvir and Daclasvir $(n=200)$.

Figure (3): illustrates that $59.7 \%$ of the studied patient with hepatitis from one year had poor quality of life before administration of treatment with Sofosbuvir and Daclatasvir medication decreased to $12.0 \%$ of them after 3 months of treatment 


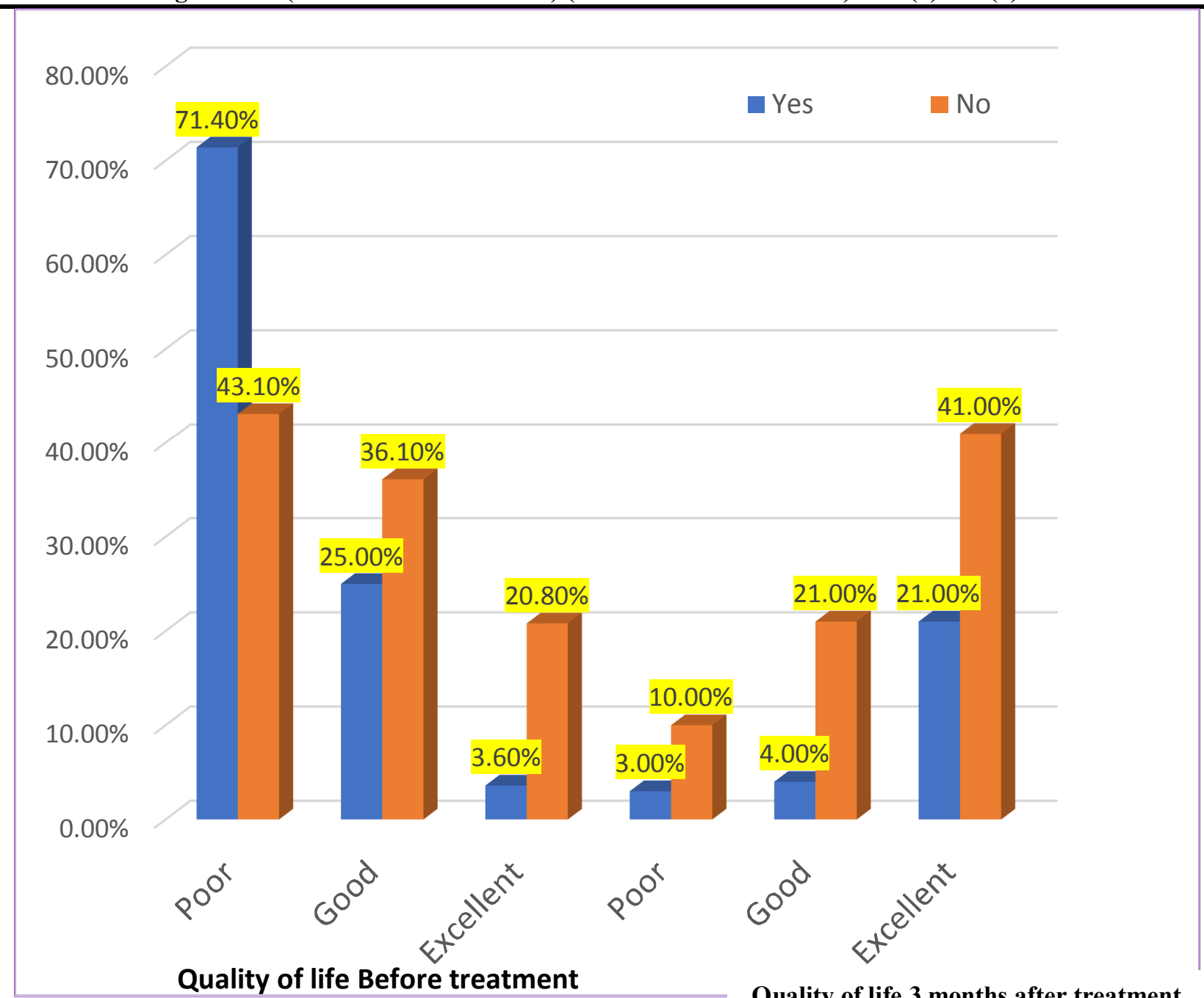

Figure (4): Comparison between total Quality of life of the studied sample and their smoking habits before and after 3 months administration of Sofosbuvir and Daclasvir $(n=200)$.

Figure (4): illustrates that $71.4 \%$ of the smoker patient had poor quality of life before administration of treatment with Sofosbuvir and Daclatasvir medication decreased to $3.0 \%$ of them after 3 months of treatment

Table (5): Correlation between bio-socio-demographic characteristics and their total quality of life measured by short-form of health before and after 3 months of Sofosbuvir and Daclatasvir administration

\begin{tabular}{|l|c|c|c|c|}
\hline \multirow{2}{*}{ Items } & \multicolumn{2}{c|}{ Quality of life before treatment } & \multicolumn{2}{c|}{ Quality of life 3 months after treatment } \\
\cline { 2 - 5 } & $\mathbf{r}$ & $\mathbf{P}$ - value & $\mathbf{r}$ & $\mathbf{P}$ - value \\
\hline Age & .183 & .068 & -.201 & .045 \\
\hline Educational level & .077 & .449 & .143 & .155 \\
\hline Occupation & .025 & .806 & .113 & .262 \\
\hline Duration of disease & $\mathbf{- . 3 2 9}$ & $\mathbf{. 0 0 1 * *}$ & .075 & .459 \\
\hline
\end{tabular}

Pearson and spearman correlation test**Correlation is significant at the 0.01 level

Table (5): reveals that there was a fair negative association between duration of disease of the studied sample with their total quality of life measured by short-form of health before administration of treatment with Sofosbuvir and Daclatasvir $(r=-.329 \& \mathrm{P}-$ value $<.001)$.

\section{Discussion}

Infection with the hepatitis $\mathrm{C}$ virus $(\mathrm{HCV})$ remains a major health problem, and the patients with hepatitis $\mathrm{C}$ virus necessitate to change their lifestyle and adopt healthy behaviors through an adjustment to a chronic medical condition, managing of symptoms and treatment health consequences, and making and maintain lifestyle changes (El-Maksoud et al., 2015).

Regarding the hepatitis patient characteristic, the present study showed their age mean $33.4 \pm 8.1$ years, less than two-third of them was male, the most of them was married, about two-fifth of them had diploma degree and the most of them had lived in the rural area.

This result comes in the line with El Niwehy et al., (2018) reported that more than half of patients aged 51-60 years with $(35.23 \pm 11.58)$ years; more than two-thirds were males; while the most of them were married and more than two-thirds were living in rural areas

As regarding education this result confirmed by Abdellatef \& Mohamed (2019) reported that more than twothird of the studied group was living in rural areas. 
This result goes in line with Kandeel et al., (2017) revealed that more than two-thirds of $\mathrm{HCV}$ patients were living in a rural areas. Also this result partially come in the line with Faddan, Soliman, \& Hassan, (2019) reported that the majority of those patients were males, less than two-third of them were from rural areas, more than three quarters were with basic education and about two-third had low socioeconomic level.

Regarding the duration of disease, the present study illustrated that near to three quarters of the studied patient, the duration of their disease from one year ago, one-quarter of them from one month, and a minority of them from one week. This result differs from (Zhang et al., 2020a) who mentioned that more than half of the patients had disease duration greater than 5 years. Also, this result comes away from Mapoure et al., (2018) reported that the median duration of HCV infection was 32 months.

As related to the smoking habit, the current study demonstrated that less than three quarters of the studied patient was not smokers. This result contradicted with Pericot-Valverde et al., (2020) reported that the majority of the patients were current cigarette smokers. This difference due to more than one third of the studied patients was female and female in the upper Egypt the most female not smoke.

As regarding the mean scores of quality of life and its domain of the studied sample on before and after 3 months from administration of Sofosbuvir and Daclasvir medication, the present study revealed that total mean score of quality of life domain after 3 months of treatment with Sofosbuvir and Daclasvir medication were higher than before treatment constitute with highly statistically significant.

This result comes in the line with Abd Elwahab Elsayed \& Abd El-Aal (2017) who mentioned that the quality of life of the patients was improved during the follow up phase than baseline before initiated the course of treatment and during the treatment regimen. Also, these results came in accordance with Youssef et al., (2017) found a significant change in HRQL across the three different periods among patients receiving DAAs before, during and at the end of therapy. Moreover, Younossi et al., (2016) found that HRQL improvement was progressive overtime after the end of treatment, with scores after 24 weeks greater than at 12 weeks.

Concerning the comparison between the studied sample regarding their total quality of life levels before and 3 months after the administration of Sofosbuvir and Daclasvir medication, the present study showed that there was improvement in total quality of life this appear through more than half of hepatitis patients were poor in quality of life before treatment with Sofosbuvir and Daclasvir medication become about two-thirds of them become excellent in quality of life after 3 months from treatment with highly statistically significant differences.

This result confirmed with Younossi \& Henry, (2015) revealed that interferon-free regimens containing sofosbuvir and ledipasvir have minimal negative effects on health-related quality of life during treatment. Also, Younossi et al., (2016) found that patients who achieved a sustained virologic response at 12 weeks after treatment reported significant improvement in their outcomes in interferon-free regimens. These results due to the patient received accurate dose of medication follow physician order, and they feel satisfaction toward medication action.

As related the relation between total Quality of life of the studied sample and their bio-scio-demographic characteristics before administration of Sofosbuvir and Daclasvir treatment, the current study showed more than twothird of studied patient who aged between 31- 40 years and more than half of the studied patient who aged between 41- 50 years had poor total quality of life before administration of treatment with Sofosbuvir and Daclasvir medication, and about three-quarter of them who had bachelor degree and near two-thirds of them who had basic education had poor quality of life before treatment with statistically significant differences. Also, more than of the studied patient with hepatitis from one year had poor quality of life before administration of treatment with Sofosbuvir and Daclasvir medication and more than two thirds of the studied smoking patient had poor quality of life before administration of treatment with a statistical significance.

These results agree with Pereira \& Fialho, (2016) reported that there was a statistical significant association between patient age and their quality of life. Also, this result was confirmed by Skevington, (2012) reported there astatically differences between patient age and quality of life.

This result comes in accordance with Zhang et al., (2020b) who studied " Health-Related Quality of Life among Patients with Hepatitis C Virus Infection: A Cross-Sectional Study in Jianping County of Liaoning Province, China " and mentioned that there were statistical significant differences between the quality of life of a patient with $\mathrm{HCV}$ and the disease years. This difference may be due studied patients not administered any therapeutic management for their disease so their quality of life was poor.

This result comes in accordance with Lynch et al., (2018) reported that smoking had a significantly larger association with moderate/severe pain (adjusted odds ratio $[$ or $]=1.50, p<0.001$ ) than among veterans without $\mathrm{HCV}$ (adjusted or $=1.26, p<0.001$ ).

Concerning the relation between total Quality of life of the studied sample and their bio-scio-demographic characteristics 3 months after administration of Sofosbuvir and Daclasvir medication, the present study revealed that there were no statistically significant total Quality of life of the studied sample and their bio-socio-demographic characteristics 3 months after administration of treatment. This result was come in the line with Kang et al., (2005) reported that there was statistical significance difference between demographic characteristics and quality of life after treatment with antiviral medication. These results may be due to the effective treatment with Sofosbuvir and Daclasvir.

Regarding the correlation between demographic characteristics and their short-form of health before and after 3 months of administration of Sofosbuvir and Daclasvir medication, the current study revealed that there was a fair negative association between duration of disease of the studied sample with their total quality of life measured by short-form of health before administration of treatment with Sofosbuvir and Daclasvir. This may be due to the length of the disease affect the deterioration of the patient's status that affects the outcome of the treatment and adversely affect the patient's quality of life.

\section{Conclusion} concluded that:

Based on the results of the present study, it can be

Total mean score of quality of life domain after 3 months of treatment with Sofosbuvir and Daclatasvir 
medication was higher than before treatment constitutes highly statistically significant.

Besides, there was a fair negative association between duration of disease of the studied sample with their total quality of life measured by short-form of health before administration of treatment with Sofosbuvir and Daclatasvir so the administration of Sofosbuvir and Daclatasvir for patients with virus $\mathrm{C}$, had a positive influence on their life, especially for newly diagnosed patients.

\section{Recommendations}

Based on the results of the present study and research questions the following recommendations are suggested:

1. Early screening for hepatitis $\mathrm{C}$ to begin early suitable treatment and minimize the effect of disease on their quality of life

2. Provide safety precaution guide before start Sofosbuvir and Daclasvir combination therapy through health education session and simple arabic brochures at outpatient clinics and hepatic centers which provide healthy life style measures regarding nutrition, physical activity, personal hygiene, drug administration.

3. Increase patients awareness regarding adverse reaction of Sofosbuvir and Daclasvir combination therapy through health education classes provided by health care team specially the nurses and encourages the patient to change their life style.

4. Further studies about factors enhancing quality of life among hepatitis $\mathrm{C}$ virus patients undergoing Sofobuvir treatment is needed.

\section{References}

(1) Abd Elwahab Elsayed, H., \& Abd El-Aal, E. M. (2017). Quality Of Life Of Chronic Hepatitis C Patients Adherent To Sofobuvir Based Regimen.

(2) Abdellatef, M. A. B., \& Mohamed, A. (2019). Effect Of Health Education Program On Life Style Of Patients With Hepatitis C Virus Receiving Sovaldi Combination Therapy. International journal of novel research in healthcare and nursing. 6(1); 933-943.

(3) El Niwehy, E., Hany, A., Mohamed, A., Moubarak, E., \& Ayed, E. (2018). Assessment Of Quality Of Life Of Hepatitis C Patients Treated By Sovaldi Drug In Viral Hepatitis Treatment Center In Ismailia Fever Hospital, Egypt. J Liver, 7(233), 21670889.1000233 .

(4) El-Ghitany, E. and Farghaly,A. (2019). Geospatial epidemiology of hepatitis C infection in Egypt 2017 by governorate. Heliyon 5 (2019) e02249

(5) El-Maksoud, M., El-Mohsen, A., Talhat, T., \& Abdalla, N. (2015). Nursing Intervention For Changing The Lifestyle Of Chronic Hepatitis C. Volume, 4, 75-83.

(6) Faddan, H. H. A., Soliman, A. M. A., \& Hassan, E. A. (2019). Correlates Of Health Related Quality Of Life Of Chronic Hepatitis C Children Attending Assiut University Children Hospital. Egyptian Journal Of Community Medicine, 37(1).

(7) Jain, A., Kalra, B. S., Srivastava, S., \& Chawla, S. (2019). Effect of sofosbuvir and daclatasvir on lipid profile, glycemic control and quality of life index in chronic hepatitis $\mathrm{C}$, genotype 3 patients. Indian Journal of Gastroenterology, 38(1), 39-43.

(8) Kang, S.-C., Hwang, S.-J., Lee, S.-H., Chang, F.-Y., \& Lee, S.-D. (2005). Health-Related Quality Of Life And Impact Of Antiviral
Treatment In Chinese Patients With Chronic Hepatitis C In

Taiwan. World Journal Of Gastroenterology, 11(47), 7494.

(9) Lynch, S. M., Wilson, S. M., Derycke, E. C., Driscoll, M. A., Becker, W. C., Goulet, J. L., . . . Bastian, L. A. (2018). Impact Of Cigarette Smoking Status On Pain Intensity Among Veterans With And Without Hepatitis C. Pain Medicine, 19(Suppl_1), S5-S11. Doi: 10.1093/Pm/Pny146

(10) Mapoure, N., Budzi, M., Eloumou, S., Malongue, A., Okalla, C., \& Luma, H. (2018). Neurological Manifestations In Chronic Hepatitis C Patients Receiving Care In A Reference Hospital In Sub-Saharan Africa: A Cross-Sectional Study. Plos One, 13(3), E0192406.

(11) McHorney CA, Ware JE, Lu JFR, Sherbourne CD. (1994). The MOS 36-Item Short-Form Health Survey (SF-36®): III. tests of data quality, scaling assumptions and reliability across diverse patient groups. Med Care; 32(4):40-66.

(12) Ministry of Health and Population, El-Zanaty and Associates \& ICF International. Egypt Health Issues Survey (2015). from http://dhsprogram.com/what-we-do/survey/survey-display480.cfm.

(13) Omran, D., Alboraie, M., Zayed, R. A., Wifi, M.-N., Naguib, M., Eltabbakh, M., . . . Eldemellawy, H. H. (2018). Towards hepatitis $\mathrm{C}$ virus elimination: Egyptian experience, achievements and limitations. World journal of gastroenterology, 24(38), 4330.

(14) Pereira, M., \& Fialho, R. (2016). Assessment Of Factors Associated With The Quality Of Life Of Patients Living With HIV/HCV Co-Infection. Journal Of Behavioral Medicine, 39(5), 767-781.

(15) Pericot-Valverde, I., Heo, M., Akiyama, M. J., Norton, B. L., Agyemang, L., Niu, J., \& Litwin, A. H. (2020). Factors And HCV Treatment Outcomes Associated With Smoking Among People Who Inject Drugs On Opioid Agonist Treatment: Secondary Analysis Of The PREVAIL Randomized Clinical Trial. BMC Infectious Diseases, 20(1), 1-11.

(16) Rand Corporation (2013). health Arabic version. Available at $\mathrm{http}: / /$ www.rand.org/health/surveys tools $/ \mathrm{mos} / \mathrm{mos}$ core 36item.h tml. Accessed 2 January 2013.

(17) Skevington, S. M. (2012). Is Quality Of Life Poorer For Older Adults With HIV/AIDS? International Evidence Using The WHOQOL-HIV. AIDS Care, 24(10), 1219-1225.

(18) Ware JE, and Sherbourne CD (1992). The MOS 36-item short form health survey (SF-36): Conceptual framework and item selection. Med Care; (1992) 30(6): 473-83.

(19) Younossi, Z., \& Henry, L. (2015). Systematic Review: Patient $\square$ Reported Outcomes In Chronic Hepatitis C $\square$ The Impact Of Liver Disease And New Treatment Regimens. Alimentary Pharmacology \& Therapeutics, 41(6), 497-520.

(20) Younossi, Z., Stepanova M., Sulkowski M., Foster G., Reau N., Mangi A., Patel K., Brau N., Roberts S., Afdhal N. (2016). Ribavirin-Free Regimen With Sofosbuvir and Velpatasvir Is Associated With High Efficacy and Improvement of PatientReported Outcomes in Patients With Genotypes 2 and 3 Chronic Hepatitis C: Results From Astral-2 and -3 Clinical Trials. Infections Disease Society of America, 36(8), 1042- 1048

(21) Youssef, N. F., El Kassas, M., Farag, A., \& Shepherd, A. (2017). Health-related quality of Life in patients with chronic hepatitis $\mathrm{C}$ receiving Sofosbuvir-based treatment, with and without Interferon: a prospective observational study in Egypt. BMC gastroenterology, 17(1), 18.

(22) Zainulabid, U. A. (2019). Association between resilience and Health-Related Quality of Life (HRQOL) among Hepatitis C patients: a study in Pahang. Kuantan, Pahang: Kulliyyah of Medicine, International Islamic University

(23) Zhang, H., Ren, R., Liu, J., Mao, Y., Pan, G., Men, K., \& Ma, L. (2020a). Health-Related Quality Of Life Among Patients With Hepatitis C Virus Infection: A Cross-Sectional Study In Jianping County Of Liaoning Province, China. Gastroenterology Research And Practice, 2020.

(24) Zhang, H., Ren, R., Liu, J., Mao, Y., Pan, G., Men, K., \& Ma, L. (2020b). Health-Related Quality Of Life Among Patients With Hepatitis C Virus Infection: A Cross-Sectional Study In Jianping County Of Liaoning Province, China. Gastroenterology Research And Practice, 2020,6716103. Doi: 10.1155/2020/6716103 